\title{
MECHANICAL CHEST COMPRESSION DEVICES AS AN OPIION FOR OUT-OF-HOSPITAL CARDIAC ARREST IN COVID 19 PANDEMIC
}

\author{
Mehdi Al-Jeabory ${ }^{1}$, Gabriela Oliwia Borkowska², Agata Olecka², Adrian Goss ${ }^{2}$, \\ Wojciech Wieczorek ${ }^{1}$, Togay Evrin ${ }^{3}$ (I)
}

\author{
${ }^{1}$ Department of Emergency Medicine, Medical University of Warsaw, Poland \\ ${ }^{2}$ Faculty of Medicine, Collegium Medicum, Cardinal Stefan Wyszynski University, Warsaw, Poland \\ ${ }^{3}$ Department of Emergency Medicine, Ufuk University Medical Faculty, Dr Ridvan Ege Education and Research Hospital, Ankara, Turkey
}

KEY WORDS: chest compression, mechanical chest compression, LUCAS, cardiopulmonary resuscitation, quality, survival rate, COVID-19, SARS-CoV-2

Disaster Emerg Med J 2021; 6(1): 50-51

We read with great interest an article by Malysz et al. [1]. In this manuscript, authors showed that over-the-head position is much more effective than standard position during chest compression. However, performing chest compressions while medical staff wears personal protective equipment (PPE) against aerosol generating procedure (AGP) may reduce the quality of resuscitation efforts. This is because of the heavy burden on medical personnel wearing PPEAGP [2]. The above thesis is confirmed by many studies [3]. At this point, as indicated by another study by Malysz et al., it is worth considering chest compressions using mechanical chest compression systems [4]. Thanks to the use of this type of devices, we obtain full standardization of chest compressions. With travel teams, when they are limited to 2-3 people, it is even more important, because then the rescuer may focus on performing other medical procedures instead of compressing the chest.

A problematic in the COVID-19 era is a significant reduction in the survival rate of OHCA patients. Ball et al. [5] analyzing the data of the Victorian Ambulance Cardiac Arrest Registry showed that survival to hospital discharge in adult OHCA patients during COVID-19 pandemic period was $6.1 \%$, while in the period before the SHD pandemic it was significantly higher and amounted to $11.7 \%$. This relationship is also confirmed by the studies of Baldi et al., where
SHD was $5.1 \%$ vs. $9.5 \%(p=0.06)$ [6]. Importantly, in the studies indicated by Baldi et al. the frequency of mechanical CPR use was significantly lower for COVID-19 period compared to pre-COVID-19 period (respectively: $6.5 \%$ vs. $16.7 \%$ ). In the study by Ball et al., however, it remained at a similar level: respectively $14.7 \%$ vs. $14.5 \%$ ( $p=0.921)$.

In summary, it is justified in accordance with the guidelines of the European Resuscitation Council on Advanced Life Support during the COVID-19 pandemic to consider mechanical chest compression to facilitate transfer/treatment [7]. Due to the results obtained by Malysz et al., in favor of the use of mechanical chest compression, consideration should be given to the routine use of this type of device in relation to OHCA patients with suspected COVID-19.

\section{REFERENCES}

1. Malysz M, Jaguszewski M, Szarpak L, et al. Comparison of different chest compression positions for use while wearing CBRN-PPE: a randomized crossover simulation trial. Disaster and Emergency Medicine Journal. 2020, doi: 10.5603/demj.a2020.0034.

2. Swaminathan R, Mukundadura BP, Prasad S. Impact of enhanced personal protective equipment on the physical and mental well-being of healthcare workers during COVID-19. Postgrad Med J. 2020 [Epub ahead of print], doi: 10.1136/postgradmedj-2020-139150, indexed in Pubmed: 33273107.

3. Kou M, Donoghue AJ, Stacks H, et al. Best Pharmaceuticals for Children Act-Pediatric Trials Network. Impact of Personal Protective Equipment 
on the Performance of Emergency Pediatric Procedures by Prehospital Providers. Disaster Med Public Health Prep. 2020 [Epub ahead of print]: 1-8, doi: 10.1017/dmp.2020.128, indexed in Pubmed: 32389152.

4. Malysz M, Dabrowski M, Böttiger BW, et al. Resuscitation of the patient with suspected/confirmed COVID-19 when wearing personal protective equipment: A randomized multicenter crossover simulation trial. Cardiol J. 2020; 27(5): 497-506, doi: 10.5603/CJ.a2020.0068, indexed in Pubmed: 32419128.

5. Ball J, Nehme Z, Bernard S, et al. Collateral damage: Hidden impact of the COVID-19 pandemic on the out-of-hospital cardiac arrest system-of-care. Resuscitation. 2020; 156: 157-163, doi: 10.1016/j. resuscitation.2020.09.017, indexed in Pubmed: 32961304.

6. Baldi E, Sechi GM, Mare C, et al. Lombardia CARe researchers. COVID-19 kills at home: the close relationship between the epidemic and the increase of out-of-hospital cardiac arrests. Eur Heart J. 2020; 41(32): 3045-3054, doi: 10.1093/eurheartj/ehaa508, indexed in Pubmed: 32562486.

7. Nolan JP, Monsieurs KG, Bossaert L, et al. European Resuscitation Council COVID-Guideline Writing Groups. European Resuscitation Council COVID-19 guidelines executive summary. Resuscitation. 2020; 153: 45-55, doi: 10.1016/.jesuscitation.2020.06.001, indexed in Pubmed: 32525022. 